\title{
A national training programme for gastroenterology and hepatology
}

\author{
M J G Farthing, R P Walt, R N Allan, C H J Swan, I T Gilmore, C N Mallinson, \\ J R Bennett, C J Hawkey, W R Burnham, A I Morris, C J Tibbs, T E Bowling, C Cobb, \\ $S$ Catnach, C Farrell, A Towle
}

\author{
The British Society of \\ Gastroenterology, \\ Training Working \\ Party, St Andrews \\ Place, London in \\ association with The \\ King's Fund \\ Development Centre, \\ London \\ M J G Farthing \\ R P Walt \\ R N Allan \\ C H J Swan \\ I T Gilmore \\ C N Mallinson \\ J R Bennett \\ C J Hawkey \\ W R Burnham \\ A I Morris \\ C J Tibbs \\ T E Bowling \\ C Cobb \\ S Catnach \\ C Farrell \\ A Towle
}

Correspondence to: Professor M J G Farthing, Digestive Diseases Research Centre, The Medical College of Saint Bartholomew's Hospital, Charterhouse Square, London EC1M 6BQ.

Accepted for publication 6 December 1995

\section{Gastroenterology and hepatology: the future}

Gastroenterologists, like many hospital specialists, are facing major changes in the way in which they work with general practitioners and develop hospital based gastroenterology and hepatology services. These changes will no doubt continue to evolve as the emphasis on primary care increases and the need for hospital specialists to provide rapid access to day care services expands. The development of new technologies such as advanced therapeutic endoscopy are putting increasing demands on gastroenterologists, while at the same time most continue to make a major contribution to general and emergency medicine services in their hospitals.

The expansion and continued evolution of gastroenterology services in the United Kingdom has prompted the council of the British Society of Gastroenterology to set up a working party to consider how future service needs will drive this evolutionary process and to anticipate the training needs of the gastroenterologist and hepatologist of the future. To assist this process, a sample of $10 \%$ of consultant gastroenterologists were questioned about their current workload and how they might wish to change their job plans in the future (Appendix I). In parallel with this, the working party considered the training requirements for the future, made proposals for a curriculum, its implementation, and methods of assessment. The working party was made aware of the results of the survey towards the end of its deliberations and took these into account during the writing of this report.

The work of the training working party was facilitated by Christine Farrell (director, clinical change programme) and Angela Towle (project manager for medical education) of the King's Fund Centre, London.

\section{Trends in healthcare that may influence the practice of medical gastroenterology and hepatology}

The working party made a fundamental assumption that medical gastroenterology and hepatology in the future will differ from the way in which it is currently practised. The working party attempted first to identify ways in which practice may change and then suggested adjustments to training programmes to satisfy future needs. A number of factors were identified that are presently under change or recently changed, which will influence both training and practice.

\subsection{The changing emphasis in primary care}

Current health policies are attempting to move much secondary care into primary care. Fund holding general practitioners wish to ensure that their patients get the most cost effective secondary care and are already requesting changes in the practice of gastroenterology and hepatology.

2.1.1 Rapid access services must be developed to provide 'one stop' diagnosis in district general hospitals.

2.1.2 Outpatient consultant opinions will be sought more often and easy, prompt access to consultants will be expected. Therapeutic decisions made by consultants may be modified by primary care physicians.

2.1.3 In rural areas, access to diagnostic facilities will need to be improved, which may involve outreach clinics, ultrasound, and endoscopy.

The exact extent of the shift of care towards primary care will determine how much change is required. In some areas it seems that there will be little change while in others important redistribution is likely. Consultants need to be trained in the development of local management guidelines and with these could oversee treatment for a number of chronic gastrointestinal disorders in general practice. The emphasis will be on outpatient consultation.

\subsection{New technology and technologists}

The endoscopic revolution from gastrocameras to video endoscopy has occurred in less than 30 years. It would not have been predicted that cholecystectomy could be performed laparoscopically or that endoscopic stent insertion for the treatment of extrahepatic cholestasis would reduce requirements for hospital beds. Digitised video images can now be transmitted transatlantically and it is 
probable that endoscopic advice may be required by telephone using such systems. Communication with general practitioners may follow similar lines with tele-clinics or 'hands-off' outpatients.

Endoscopists are likely to be trained from a non-medical pool in the foreseeable future in attempts to improve service, reduce costs, and provide more outpatient time for consultants. A greater proportion of the endoscopy practised by gastroenterologists is likely to be more therapeutic and time consuming, but time may be made available by reducing the diagnostic load.

Screening for colonic cancer is likely to develop in one form or another. A non-invasive screening tool (genetic/molecular) will probably become available and will re-focus the need for colonoscopy, but until such time colonoscopy will continue to be a growth area. Time and personnel need to be made available for this.

\subsection{Audit and evidence based outcomes}

Present outcome audit is rudimentary, but pressure is being applied by the Royal Colleges to audit and purchasers are going to direct resources to the most effective units. Consultants need to be involved in developing the right measures and identifying the problems (case-mix, racial, social, and environmental), which in turn affect outcome measures. This activity will be time consuming and personnel will be required. Training in audit technology is needed.

\subsection{Subspecialisation and the implications for secondary and tertiary care}

Fewer but larger hospitals are likely to remain after the present round of reorganisations and purchasing authorities are likely to merge. These hospitals will have more consultants with a greater outpatient and investigative role but may have fewer beds. In such an environment gastroenterological groupings are likely to include individuals who specialise in certain gastrointestinal areas - liver, inflammatory bowel disease, nutrition, etc. Internal management guidelines will be just as important as in general practice. The opportunity will exist for surgeons, pathologists, radiologists, specialist nurses, and technicians to work in multispecialty teams with gastroenterologists and hepatologists.

There is increasing demand to re-group certain conditions, for example gastrointestinal cancer. In this case a specialist gastrointestinal oncologist may be needed to work in association with a gastroenterologist who will provide continuing care.

\subsection{Increasing requirements for general and emergency medicine}

There is an increasing number of hospital emergency admissions and gastroenterologists have traditionally participated fully in the receipt of such cases. The need will remain but gastroenterologists' time will be eroded through provision of increasing outpatient and endoscopic services. Most gastroenterologists accept that they will continue to participate in the general medical service but some will probably opt out. Thus there will be a need to ensure that most trainees have adequate experience in general medicine and to identify training schemes for subspecialist gastroenterologists.

\subsection{Demography}

An increasing elderly population with experience of high tech medicine will pressurise against agism. Colon cancer surveillance programmes for example may not be age restricted. Patients with gastrointestinal disorders will have multiple conditions and gastroenterologists will be expected to be able to deal with them. Endoscopic gastrostomy feeding could become standard practice in many conditions of the elderly associated with poor appetite.

\subsection{Postgraduate training and research}

Reduction in junior doctors' hours is widely supported but will probably have a detrimental effect on the aspect of training that comes from direct consultant supervision. Patient care may deteriorate through lack of continuity when provided solely by consultants because of inadequate replacement of lost hours. The pressure will divide loyalties to gastroenterology (predominantly outpatient and easily controlled) and general medicine (mostly inpatient and uncontrollable). Solutions could be more prolonged training, which goes against The Royal College of Physicians recommendations and European Commission and government directives, or massive consultant expansion including part time posts, with more handson general medical involvement.

An important and expanding managerial role has already developed in gastroenterology, with consultants often managing teams of endoscopists, nurses, stomacare nurses, and administrative staff. Consultants require training in this area. As training becomes formalised, consultants will need support and opportunities for improving their own skills as a trainer. The need for continuing medical education will include these areas in addition to those of medical and gastroenterological clinical practice.

The research emphasis will tend to be into the health services: health provision, identification of needs, outcomes, and cost effectiveness. This assumption is borne out by the 'health services research initiatives'. Basic science research had traditionally played a part in the training of many gastroenterologists. The importance of some formal training in research methods may subsume the previous emphasis on attaining a higher degree through research for some, while a few will have the opportunity for extended basic research training. 


\section{Structure and process of training in medical gastroenterology and hepatology}

\subsection{Objectives}

3.1.1 To provide a comprehensive and structured higher medical training programme in gastroenterology for those who have completed general professional training to equip them for specialist practice in gastroenterology.

3.1.2 To enable trainees to reach agreed standards of quality and satisfy the assessment process.

3.1.3 To encourage flexibility in content and duration (full time or part time) so that those who show special aptitude for teaching, research or detailed subspecialist work may pursue this, subject to sufficient career opportunities after completion of training.

At present the government devolves responsibility for setting and maintaining standards of training for junior medical staff to the Royal Colleges. The three Royal Colleges of Physicians discharge this responsibility through the Joint Committee on Higher Medical Training (JCHMT), which in turn looks to individual Specialty Advisory Committees (SACs) for approval of training programmes and accreditation of trainees who have satisfactorily completed such programmes.

The SACs draw their membership from both the Colleges and from the specialist societies; hence the SAC in gastroenterology has three members from the BSG and three from the Colleges, acknowledging the importance of the specialist society in this function of setting training standards. At local level, postgraduate deans, in consultation with college regional advisers, have responsibility for assessing higher trainees annually and overseeing their programmes.

In recognition of the increasing complexities and demands that accompany the more structured 'post-Calman' training programmes, the JCHMT wishes to strengthen the regional network by putting in place for each specialty such as gastroenterology a regional programme director, nominated by the postgraduate dean and approved by the JCHMT. This fits in well with the independent conclusions reached in this document for the supervision and assessment of trainees.

\subsection{Structure of training posts}

To cater for the varied needs of individual trainees, a modular training structure is proposed with a Core module and a series of Option modules (see 4.2.1 and 4.2.2). This structure will allow trainees to develop their own interests within the subject while ensuring that they have a broad background in both gastroenterology and general medicine. It is anticipated that dual certification in gastroenterology and general medicine will require a five year training course. Training will aim to provide dually accredited trainees who would be pluripotential, fulfilling future teaching hospital, district general hospital, and academic needs. Flexibility is the key to this arrangement.
3.2.1 Core: Core training in gastroenterology would be two and a half years in general medicine and gastroenterology concurrently. Trainees would also be expected to complete a further 30 months in Option modules in gastroenterology/hepatology. Training would therefore be completed in five years giving dual accreditation in general medicine and gastroenterology.

3.2.2 Options: proposed optional subjects are listed in Section 4.2.2. Depending upon the option, it is anticipated that three to six months will be required to reach competence in a given option. Trainees wishing to specialise in a particular aspect of gastroenterology or hepatology will be able to choose to spend longer in that field to achieve excellence. In many instances this will be for a year. However, those wishing to specialise as clinical academics, hepatologists or advanced endoscopists may choose to spend the entire 30 months available for options training in research, hepatology or endoscopy.

Some of the Option modules may be provided by other disciplines and surgeons, radiologists and pathologists may participate in those modules.

Training in the option modules will generally take place during the working day. Trainees will be required in addition to join general medical rotas for out of hours work. This will be important to ensure: (a) that option module training does not compromise hospital rotas; (b) that concurrent training in general medicine and gastroenterology can take place.

To facilitate the organisation of a weekly time table the options may be taken as whole time (four days per week), half time (two days per week) or quarter time (one day per week).

Throughout the Core training period the trainee will be expected to undertake selfdirected study to ensure that the theoretical aspects of the subject are learnt. Self-directed learning should be supplemented by regionally based teaching programmes.

\section{Entry to the training programme}

Entry to the specialist registrar grade in gastroenterology will be by open competition and interview before a properly constituted advisory appointments committee for each group of training hospitals. The advisory appointments committee should consider applicants for both full time and part time training. Candidates will have the $\mathrm{MRCP}(\mathrm{UK})$ and have completed general professional training.

\subsection{Regional programme director}

There will normally be one programme director for each region (as defined by the area covered by a regional postgraduate dean) who will be responsible for implementation of the curriculum and delivery of a planned, progressive programme of training and education through agreed standards of quality and quantity. 
The regional programme director will be appointed by the postgraduate dean with the advice of the trainers. S/he will be responsible to the postgraduate dean and maintain links with the Royal College regional adviser.

The programme director will have the following responsibilities:

(a) To plan a programme of training containing both core and appropriate options in conjunction with the trainee and the local educational supervisors. The programme director should ensure that the training provided is likely to meet the needs of most hospitals to maximise the chances of appointment to a consultant post at the end of the training programme. Links with the manpower coordinator of the British Society of Gastroenterology and Royal College of Physicians gastroenterology committee will be essential to ensure that this goal is achieved.

(b) The training programme will almost inevitably involve rotation between hospitals, which will require supervision by the programme director.

(c) The programme director should ensure that the experience in each post fulfils the stated requirements for that period of training (module).

(d) The programme director will need to liaise with the trainee, trainer or local education supervisor, and other bodies in the event of problems with the trainee or the training post.

(e) The programme director will arrange and facilitate the assessment of each trainee at appropriate intervals - probably yearly.

In view of the responsibilities of the regional programme director in decisions, coordinating and assessing training in gastroenterology and hepatology it is anticipated that two sessions will be required each week to complete the task, and a source(s) of funding will need to be identified to support this activity.

\subsection{Trainer}

The trainer will be one of the consultant staff on the firm or in the department to which the trainee is attached and will usually have day to day contact with the trainee. The trainer will plan a weekly programme, agreed with the regional programme director and the trainee, which will provide an appropriate balance between training and service commitments. Training commitments will include time for academic meetings, audit, self-directed learning, research, study leave, and supervised service. The trainer will also arrange for regular assessments of the trainee (see section 5).

\subsection{Trainees}

The trainee should agree and implement a weekly time table with the local trainer and the regional programme director. The trainee should ensure that there is a formal meeting with the trainer every three months and that any problems with training are identified and resolved in good time. The trainee should keep a record of practical procedures in a personal training record and ensure that the experience from the post will fulfil the stated requirements for that period of training. Any problems that are not resolved locally should be reported promptly to the regional programme director or failing this, the Specialist Advisory Committee. Trainees should see and sign any formal reports or assessments about their training.

\subsection{Alternatives to full time training (flexible training)}

There is increasing demand for periods of less than full time training in all medical specialties. All training programmes in medical gastroenterology/hepatology must have posts available for trainees wishing to work part time at any stage in the programme. These trainees must apply through a specifically designated officer appointed by each regional postgraduate dean to oversee part time training. Competition for posts on regional part time training programmes must be alongside full time applicants and appointments made by the same advisory appointments committee, although a separate committee may be needed if no appointments to full time regional trainee posts are made within six months of application for a part time post. A part time trainee will be required to work a minimum of half time but may work further hours up to full time but all Option modules should be available on a less than full time basis. Part time trainees should have equal access to each of the Core and Option modules of a training scheme as full time trainees and the same commitment from trainees and regional programme directors. It would be expected that flexible trainees will have a regular on call commitment.

The frequency of assessments for trainees will depend on the numbers of hours worked. The progress of their training will be considered in terms of the numbers of hours committed to each Core or Option module unless this can be defined in terms of numbers of procedures (for example, endoscopy) or the acquisition of a precise skill (for example, imaging).

\subsection{Outcome}

Trainees completing the training programme whether full time or part time, would be qualified to practise general and emergency medicine and general gastroenterology/hepatology. In addition, the programme is sufficiently flexible to permit further specialisation within the field of gastroenterology and hepatology, allowing the development of individuals with a major commitment to: (a) academic gastroenterology/laboratory science; (b) hepatology; (c) advanced endoscopy.

\subsection{Recommendations}

3.8.1 Regional programme directors in gastroenterology/hepatology should be appointed under the auspices of postgraduate deans and in conjunction with trainers.

3.8.2 It is anticipated that two sessions each 
week will be required to devise and oversee a regional programme and thus sources of funding to support regional programme directors will need to be identified.

3.8.3 The funding of part time posts will have to be clarified in relation to the funding of all career grade medical gastroenterology/hepatology posts.

\section{A curriculum for training in medical gastroenterology and hepatology}

\subsection{Aims}

4.1.1 To produce gastroenterologists who are clinically skilled and sufficiently competent to provide a general gastroenterological and hepatological service.

4.1.2 The training programme should have flexibility to encourage a degree of specialisation and choice commensurate with career aims and service needs, and enable the trainee to face the changing needs of gastroenterology in the NHS.

4.1.3 The training should encourage a critical and analytical approach to effective clinical management and a positive approach to health service management, teaching, and research.

\subsection{The curriculum}

The curriculum should be divided into Core and Option modules. The Core of the curriculum will provide education in the theoretical basis of, and training in, the clinical care of patients with common gastroenterological conditions in the inpatient and outpatient setting. Such training will include basic diagnostic and therapeutic endoscopic and investigational skills, in harmony with European trends and consistent with the relevant EEC Directive 13/93.

\subsubsection{Core}

\subsubsection{Scientific basis}

During specialist training the trainee should acquire sound scientific and theoretical knowledge of the normal structure and function of the gastrointestinal tract as well as knowledge of the aetiology, pathogenesis, natural history, clinical presentation, investigation, and treatment of diseases of the gastrointestinal tract, including the hepatobiliary system and pancreas. Such knowledge includes histopathology, haematology, microbiology and parasitology, chemical pathology, immunology, genetics, molecular biology, epidemiology, and statistics. An understanding of medical demography and health care economics is required.

\subsubsection{Clinical knowledge}

The trainee will be expected to have a broad based education in most areas of gastroenterology. Knowledge of the indications and contraindications for, and the complications of, various imaging, investigational, and surgical techniques together with understanding of their limitations will be essential in a variety of clinical settings.

All training will fulfil the requirements of the Specialist Advisory Committee in Gastroenterology and the Joint Committee on Higher Medical Training.

4.2.1.2.1 General and emergency medicine. 4.2.1.2.2 Core gastroenterology (to include the inpatient and outpatient management of the following): (a) inflammatory bowel disease; (b) hepatobiliary disease (acute and chronic liver disease, jaundice and alcohol related disorders); (c) functional bowel disorders; (d) malabsorption and pancreatic disease; (e) gastrointestinal infections and AIDS; (f) oesophageal and gastroduodenal disease; (g) oncology (oesophageal, gastric, pancreatic, and colon cancer); (h) gastrointestinal emergencies (acute abdomen, bleeding, fulminant colitis, cholangitis); (i) nutritional support; (j) gastroenterological manifestations of systemic disease.

\subsubsection{Clinical care and expertise}

Trainees should have supervised practical experience in the clinical care of patients in the above groups, both as inpatients and outpatients. The clinical management of patients in the primary care setting and at home should be understood. Clinical experience must be gained mainly in substantive posts with appropriate development of clinical responsibility. Teaching by direct supervision of clinical work and attendance at multidisciplinary meetings must be an integral part of the training programme. Pharmacological, psychological, dietetic, and surgical treatments available for the above conditions will need to be understood and experience gained in their use.

\subsection{Competence/skills required}

To treat patients with these conditions training will be required in the following skills:

(a) Diagnosis and treatment;

(b) Basic diagnostic endoscopy. This should include rigid sigmoidoscopy, oesophagogastroduodenoscopy and colonoscopy, and possibly exposure to endoscopic retrograde cholangiopancreatography. Principles of disinfection, safety, and sedation;

(c) Basic endoscopic therapeutic techniques. This should include stricture dilatation, injection or banding of varices, or both, haemostatic techniques and polypectomy. The indications, contraindications, and complications of these procedures should be understood;

(d) Communication skills. Trainees should acquire an attitude to, knowledge of, and skill in doctor/patient communication and the management of communication in hospital and beyond. This should include basic communication skills, information giving, negotiating, writing comprehensible prepared material, participating in hospital-wide communication initiatives and working in a multidisciplinary team;

(e) Cancer care. This should include palliative 
care and palliative techniques, pain relief, terminal care, informing patients, psychological support, counselling, management of bereavement and ethics;

(f) Non-endoscopic techniques. This should include liver biopsy, paracentesis, and knowledge of other investigative techniques used in gastroenterology and hepatology;

(g) Management training. This should include experience of audit, information technology, Health Service management, contracting, and marketing.

\subsubsection{Option modules}

The trainee will be required to undertake a variety of advanced option modules (clinical and research) after discussion with the regional training supervisor. Some of the options will be full time whereas others will be part time and permit training in both Core and Option to run concurrently.

All options will include training in the teaching of patients, nurses, medical students, and doctors relevant to that module.

(a) Advanced gastroenterology (experience in specialist units such as inflammatory bowel disease, or coloproctology, or oesophageal disease).

(b) Advanced hepatology (management of fulminant hepatic failure, transplantation, specialist hepatitis referral centre).

(c) Physiological measurement (oesophageal manometry and $\mathrm{pH}$ measurements, gastric and pancreatic function testing, anorectal physiological studies).

(d) Nutrition (assessment of requirements, catheter placement, nutrition team service management).

(e) Paediatric and adolescent liaison gastroenterology (to acquire experience in gastroenterological conditions that start in childhood and continue into adulthood).

(f) Advanced therapeutic endoscopy (ERCP, or laser therapy, or photodynamic therapy, or management of strictures and fistulas, or enteroscopy).

(g) Imaging (ultrasound, endoscopic ultrasound, computed tomography, magnetic resonance imaging, nuclear medicine).

(h) Cancer care (drug therapeutic regimens, radiotherapy, combined modality treatment, and brachytherapy of all common gastrointestinal and hepatic malignancies).

(i) Palliative care (pain relief, hospice care, terminal care, palliative endoscopic techniques).

(j) Communicable disease (advanced AIDS, intestinal infection, hepatitis, tropical disease, parasitology, special experience with Helicobacter pylori).

(k) Psychological medicine (basic liaison psychiatry; the knowledge of psychiatric disease in hospital patients and the nature and management of physical symptoms with no organic basis. Eating and drinking disorders, factitious disease).

(l) Research: basic (experimental design, basic techniques, statistical planning, critical appraisal). (m) Research: advanced I (cellular/molecular biology), II (whole organism pathophysiology), or III (clinical trials/epidemiology).

(n) The interface between primary and secondary care in gastroenterology.

(o) Teaching and presentation skills (including training in presentation, educational methods, audiovisual techniques, media management, information technology).

(p) Health service management (audit, information technology, budgeting, contracting, negotiating skills, personnel management, marketing).

(q) Elective free option (for example, 'pure' epidemiology, genetics, microbiology).

\subsection{Practical experience}

The Core curriculum will run during the first 30 months of specialist training. Trainees will in addition be required to undertake several Option modules during their training to meet their own educational and clinical interests, as well as their career aims.

The number of Option modules available in each region will vary, and arrangements will need to be made to permit as much choice as possible. The total number of Option modules should remain flexible and dependent on career intentions. It is anticipated that in many cases the Option modules and Core curriculum will run simultaneously.

The number of practical procedures that are undertaken by the trainee will be in line with that advised by the Joint Advisory Group on Endoscopic Training.

\subsection{Recommendations}

4.4.1 Training in gastroenterology and hepatology should be a basic five year programme with the option of an additional year to permit flexibility in clinical training and research.

4.4.2 The training programme should consist of a compulsory Core component and broad range of Option modules to enable trainees to structure their training towards a variety of career outcomes.

4.4.3 The Core will consist of 30 months' training in gastroenterology and hepatology concurrently with general and emergency medicine. Options will require a further 30 months, each having a minimum duration of three and a maximum of 12 months whole time equivalents and a further optional one year may be taken for research.

4.4.4 The training programme will produce broadly trained gastroenterologists/ hepatologists but in addition will enable some trainees to gain special expertise to pursue careers in academic gastroenterology (including clinical and basic science), advanced hepatology, and advanced endoscopy.

4.4.5 The British Society of Gastroenterology should develop a syllabus for the training programme to cover the theoretical basis of the practice of gastroenterology/hepatology.

4.4.6 Approaches to implementing this syllabus should be investigated with consideration given to both self-directed learning (for 
example, by the development of interactive computer based learning programmes) and by the development of a regionally based teaching programme to complement for former.

\section{Methods of assessment}

\subsection{Training unit and the trainer}

Current Guidelines and Practice by The Specialist Advisory Committee of Unit Assessment will be adhered to. A unit will be deemed suitable if:

(a) there are a minimum of two consultant gastroenterologists or, if only one, adequate cover arrangements, so that day to day practice can realistically be supervised;

(b) there should be at least one half of the work undertaking supervised clinical responsibilities such as endoscopy lists, ward rounds, and outpatient clinics;

(c) it is able to provide facilities to permit the best standards of specialist practice, including facilities for appropriate clinical investigation and management;

(d) there are adequate opportunities to gain clinical experience as indicated by outpatient and daycase attendances and completed consultant inpatient episodes;

(e) there are adequate library facilities and other forms of academic support;

(f) adequate study leave is provided in the form of day release and for longer training courses within or outside the region.

Currently, the specialist advisory committee undertake unit assessments every five years. In addition to these the postgraduate dean or representative and the regional programme director, who will be a gastroenterologist/hepatologist, will validate the unit and trainer on an annual basis. The postgraduate dean may elect the regional programme director to be his representative. These annual assessments will need to ensure:

(a) The unit and trainer are fulfilling the requirements of the core curriculum and any option modules they may be covering.

(b) The trainee is receiving trainer assessment and adequate supervision on a day to day basis. At these annual assessments the trainee will be given the opportunity to give unbiased feedback on trainer and unit, which will subsequently be fed back to the trainer by the regional programme director or the regional postgraduate dean, or both.

It will be the responsibility of the postgraduate dean to ensure that the trainer is adequately prepared to be a trainer. Provision of training courses for trainers may be required.

\subsection{Trainee Assessment}

\subsubsection{Local}

On arrival in post there will be a 'formative' first appraisal assessment by the trainer which will:

(a) Determine educational needs with respect to the Core curriculum for Option modules offered by the particular training unit. The personal training record will be used to assess the trainee's progress and to identify gaps in experience. The needs of a first year trainee will be different from a third or fourth year trainee. Difficulties in achieving training goals will be identified.

(b) Set future training goals on the basis of need. Goals will be set and agreed upon between trainer and trainee, documented, and signed by both. This will be an informal process.

A second 'summative' appraisal interview with the trainer will take place either one year later or at the end of the post, if this is shorter. The summative appraisal will:

(a) determine the extent to which trainee goals have been achieved;

(b) examine the personal training record with the trainer signing the trainee up for the various skills attained;

(c) assess trainee competence including strengths and weaknesses;

(d) set new goals.

A written record of the experience and training of each trainee must be maintained and agreed by both trainer and trainee, in advance of the annual assessment organised by the postgraduate dean. This will form part of a report containing also an assessment by the trainer of the trainee's technical ability on an agreed scale. The report will also show the trainee's ability to work as a member of a multidisciplinary team and their ability to relate to and communicate with patients and other staff at all levels. The aim should be to ensure that the trainee is developing these and other skills (for example, management) essential for consultant practice in the NHS.

In addition to this formal assessment at local level, informal continuous assessment will continue on a day to day basis during:

(a) At least one consultant led ward round per week.

(b) Outpatient clinics, in which the trainer might join the trainee during consultations on a monthly basis.

(c) Endoscopic training suggested by the Specialist Advisory Committee guidelines (Appendix II).

(d) Regular multidisciplinary meetings (radiology, histopathology, etc) and journal review sessions.

\subsubsection{Regional}

Trainees will be assessed annually at an interview organised by the postgraduate dean with the college regional adviser as chairman. Other members would normally include the regional programme director, another consultant in gastroenterology not directly connected with the training scheme or unit, and a consultant physician from another specialty where the training also involves general (internal) medicine.

The trainer will also be asked to evaluate the competence of the trainee. As a result of this assessment a written report would be prepared, signed by the trainer, trainee, and regional 
postgraduate dean/regional adviser. A copy will be kept by each as well as one sent to the JCHMT. At the penultimate annual assessment, the panel will include a gastroenterologist from outside the region nominated by the JCHMT. This assessment would permit identification and correction of problems with the aim of avoiding an adverse final assessment.

If the trainer or the regional programme director feel that the trainee is failing in any respect, or the trainee wishes to opt out of the training programme, it will be the responsibility of the regional programme director to organise appropriate career counselling. At this annual interview the trainee will have the opportunity to give feedback on the unit and trainer.

At the end of training, a final summative appraisal will be undertaken in a similar format and the report sent to the JCHMT and CCST to enable certification.

A final 'exit' examination for trainees at the end of the training period was felt undesirable but that standards could be maintained by continuous self-assessment by the trainees and by the trainers.

\subsubsection{Appeals procedure}

If there is a dispute between trainer and trainee on the description of experience, training or performance, arbitration will be coordinated by the postgraduate dean and the SAC. If the final assessment is unsatisfactory, an appeal mechanism independent of the JCHMT and postgraduate deans should come into play. The British Society of Gastroenterology may wish to assist this process.

\section{Summary}

The council of the British Society of Gastroenterology commissioned this report from a working party set up to examine future training in gastroenterology. The need for re-examination of training was driven by two considerations - the rapid changes in healthcare organisation in Britain, and by accelerating technological progress in diagnosis and treatment of gastrointestinal conditions.

The predominant organisational changes are the trend towards increasing primary care supported by ready access for general practitioners to diagnostic tests; outreach clinics by consultants and prompt access to appropriate, cost effective secondary care; yet higher levels of emergency acute admissions. The aging population and the necessity to provide technologically appropriate care for them is an important demographic trend.

Technologically it seems likely that change will be even more rapid over the next 30 years than it has been in the past 30 years; this makes prediction difficult, but undoubtedly endoscopic techniques - both diagnostic and therapeutic - will increase in number and safety.

\subsection{Patterns of training}

The training pattern proposed is based on a more structured core of scientific education than now, partly achieved by 'distance learning' techniques, with periods of self-assessment. This core scientific knowledge will be the basis for clinical experience in approved units, with as much emphasis on consultative skills as on technical achievement. Appropriate exposure to general internal medicine (including acute admissions) as well as Core gastroenterology will be assured. Training will be supervised, recorded, and appraised.

In addition to this essential Core, there will be a number of Option modules covering advanced areas of clinical gastroenterology, endoscopy, psychology and epidemiology, research, etc. Every trainee will undertake several such modules, the pattern being determined by agreement between the trainee and supervisor.

\subsection{Structure of training}

The training programme has been designed to fit in with the reduced hours of work/training likely to be acceptable in the future. Core gastroenterology training would run concurrently with general medicine for 30 months during training. A trainee would be expected to have completed a further 30 months' training in Option modules before applying for consultant posts.

The necessary organisation of this complex scheme would be the responsibility of a regional programme director under supervision of the regional postgraduate dean. There would be local educational supervisors (trainers) and regular feedback sessions between them.

To ensure that this compressed training programme will have the right outcome, the units providing training and the trainers will need regular assessment (by the SAC every five years and the regional postgraduate dean and regional programme director annually). The trainee will also be assessed annually by local trainers and by the regional postgraduate dean or regional programme director. On all these occasions a written report will be prepared with copies kept by trainer and trainee.

\subsection{Outcomes}

The final product will be three types of gastroenterologist. The trainee with a minimum number of hours in a broad range of modules would be a 'general physician/gastroenterologist'. Others would be 'specialists' with a broad general training, but with more specialist training in a smaller number of modules in areas such as nutrition, oncology, management. Finally there would be 'super-specialists' who would have spent most of their modular option training in one area such as research, hepatology or advanced endoscopy.

The days of clinical apprenticeship - 'picking it up as you go along' - are over. Training in the future must be at once faster, yet more comprehensive; stimulating yet better supervised. The changes envisaged make considerable demands on future trainees, but require 
even greater changes in attitude, expectation, and training ability from existing consultants. These will not easily be achieved along with the many other rapid changes demanded of senior professionals, but the force for such change is irresistible.

This working party report was accepted by the training committee of the British Society of Gastroenterology and approved by the council of the British Society of Gastroenterology in December 1995.

Members of the training working party

M J G Farthing (chairman), secretary, British Society of Gastroenterology; R P Walt, secretary, BSG; R N Allan, Royal Colle of Phys; R P Walt, secretary, BSG; R N Allan, Royan, College of Physicians gastroenterology committee; $\mathrm{CH}$ J Swan, T Gilmore, specialist advisory committee in gastroenterology, C N Mallinson, European board of gastroenterology of the EUMS; J R Bennett, BSG clinical services committee; C J Hawkey, BSG education committee; W R Burnham, BSG manpower office; A I Morris, BSG endoscopy training officer; $\mathrm{C} \mathrm{J}$ Tibbs, T E Bowling, association of gastroenterologists in training; C Cobb, S Catnach, co-opted as representatives of flexible training in gastroenterology; C Farrell, director, clinical change programme, King's Fund Development Centre; A Towle, project manager, medical education, Kings' Fund Development Centre.

\section{Appendix I}

\section{King's Fund Centre}

Gastroenterologists: present and future needs

\section{The sample}

Questionnaires were sent to 69 gastroenterologists in the United Kingdom. This represents a $10 \%$ sample of all the physician gastroenterologists on the British Society of Gastroenterologists' (BSG) membership list. The response rate was $77 \%$. Time prevented a follow up letter to increase this response.

\section{Profile of respondents}

Age

A quarter $(26 \%)$ of the respondents were aged 40 or below; a third $(34 \%)$ were between 41 and 50 ; just under a third $(31 \%)$ were between 51 and 59 ; and $9 \%$ were 60 and over. All but two were men. Everyone in the sample had reached consultant level before the age of 40 , with $70 \%$ appointed by the age of 35 .

\section{Hospital type}

Four of $10(40 \%)$ were working in teaching hospitals; the rest in district general hospitals.

Replies were received from gastroenterologists in all regions.

\section{Components of work}

Table I shows how respondents divided time between the different aspect of their jobs. Nearly two thirds $(63 \%)$ of the sample spent either $10 \%$ or $20 \%$ of their time on general medicine. A similar proportion $(66 \%)$ spent up to $30 \%$ of their time on gastroenterological work. Nine of $10(93 \%)$ spent up to $30 \%$ of their time on endoscopy. Only one in five $(21 \%)$ spent any time on nutrition. Four fifths $(79 \%)$ spent up to half their time on management duties.
TABLE II Changes to time spent on general medicine

\begin{tabular}{lrr}
\hline & Number & $\%$ \\
\hline Stop all general medicine & 12 & 41 \\
Reduce \% & 12 & 41 \\
Stay with current \% & 2 & 3 \\
Increase \% & 2 & 3 \\
Doesn't do general medicine & 1 & 2 \\
Total & 29 & 100 \\
\hline
\end{tabular}

TABLE III Respondents wish to spend more or less time on specific aspects of their current jobs

\begin{tabular}{lcc}
\hline fob components & $\begin{array}{c}\text { Wish to spend } \\
\text { more time on (\%) }\end{array}$ & $\begin{array}{c}\text { Wish to spend } \\
\text { less time on (\%) }\end{array}$ \\
\hline General medicine & 4 & 45 \\
Gastroenterology & 28 & 2 \\
Endoscopy & 9 & 17 \\
Nutrition & 19 & 2 \\
Management & 4 & 30 \\
Teaching & 11 & 11 \\
Research & 45 & 0 \\
Private practice & 7 & 13 \\
No desire to change & 43 & 43 \\
No response & 2 & 2
\end{tabular}

Number $=53$ (totals do not add to $100 \%$ because more than one choice was available).

Four of five consultants $(79 \%)$ did some private practice, with three quarters $(79 \%)$ of these spending $10 \%$ of their time on it.

Over half the respondents (59\%) engaged in research with most spending $10 \%$ of their time on it.

\section{Desire for change}

Twenty three respondents $(43 \%)$ said that they were content with the way their current activities were disposed; and one other person did not reply to this question. These 24 people are excluded from the following analysis, which records the changes that the 29 malcontents wished to make.

\section{General medicine}

Almost all the people who wished for change wanted either to stop doing general medicine altogether or to reduce the amount of time they spent on it; $41 \%$ in each case. Most of those who wished to reduce the time, wanted to reduce it from $20 \%$ to $10 \%$, although there were three who were doing more than $20 \%$ general medicine who wished to reduce the time spent to $20 \%$. Two respondents wanted to increase the amount of time spent on general medicine by $10 \%$. Table II shows the exact proportions.

Gastroenterology

The majority wish to remove or reduce time spent on general medicine was primarily to allow people to spend more time on other activities not always gastrointestinal. In this case, $11(38 \%)$ respondents wanted to keep the same proportion of time for gastroenterology, usually at $30 \%$. Fifteen people $(52 \%)$ wanted to increase the amount of time they spent on it by $10 \%$ or $20 \%$. One person wanted to reduce the time by half to $15 \%$.

TABLE I Proportion of sample spending time on different aspects of their jobs

\begin{tabular}{lcccccccc}
\hline $\begin{array}{l}\text { \% Of } \\
\text { time spent }\end{array}$ & $\begin{array}{l}\text { General } \\
\text { medicine } \\
\%\end{array}$ & $\begin{array}{l}\text { Gastroenterology } \\
\%\end{array}$ & $\begin{array}{l}\text { Endoscopy } \\
\%\end{array}$ & $\begin{array}{l}\text { Nutrition } \\
\%\end{array}$ & $\begin{array}{l}\text { Management } \\
\%\end{array}$ & $\begin{array}{l}\text { Teaching } \\
\%\end{array}$ & $\begin{array}{l}\text { Research } \\
\%\end{array}$ & $\begin{array}{l}\text { Private } \\
\text { practice }\end{array}$ \\
\hline None & 7 & 0 & 2 & 79 & 21 & 11 & 41 & 21 \\
$<10$ & 0 & 0 & 0 & 6 & 6 & 8 & 6 & 0 \\
10 & 21 & 7 & 15 & 15 & 43 & 66 & 45 & 62 \\
20 & 42 & 19 & 43 & 0 & 17 & 9 & 6 & 15 \\
30 & 17 & 40 & 35 & 0 & 9 & 2 & 0 & 2 \\
40 & 9 & 10 & 0 & 0 & 2 & 2 & 2 & 0 \\
50 & 2 & 0 & 3 & 0 & 2 & 2 & 0 & 0 \\
60 & 0 & 6 & 0 & 0 & 0 & 0 & 0 & 0 \\
70 & 2 & 7 & 0 & 0 & 0 & 0 & 0 & 0 \\
80 & 0 & 7 & 0 & 0 & 0 & 0 & 0 & 0 \\
90 & 0 & 4 & 0 & 0 & 0 & 0 & 0 & 0 \\
100 & 0 & 0 & 0 & 0 & 0 & 0 & 0 & 0 \\
Number=100\% & 53 & 53 & 53 & 53 & 53 & 53 & 53 & 53 \\
\hline
\end{tabular}


Questionnaire

Gastroenterologists: present and future needs

Please tick appropriate box or write in your answer

1. Gender

Male

Female

2. Age last birthday:

3. Age at qualification

4. Age appointed consultant

5. Type of hospital

Teaching

Other:

6. Regional Health Authority

7. How many gastroenterologists work in your hospital/trust?

(a) Actual number

(b) Full-time equivalent number

(c) Level of staff:

consultant(s)

senior registrar(s)

Other:
Endoscopy

Those who wanted to change the proportion of time they spent on endoscopy (14 in all) either wished to increase it (5) or reduce it (9). Those who wanted to increase the time spent on endoscopy were usually spending sizeable proportions of their time on it and none of them wanted to reduce it to less than $20 \%$ or $30 \%$. Satisfaction with endoscopy seemed to be highest when the proportion of time spent on it was $30 \%$.

\section{Nutrition}

Table I showed that only one in five respondents spent any time on nutrition. This seemed to be the way people liked it as only 11 respondents wished to change it. Ten of these 11 people wanted to spend up to $10 \%$ more of their time on nutrition up to a maximum of $20 \%$. One person who was spending $10 \%$ of his time on it wanted to stop doing it altogether.

\section{Management}

Altogether 18 people wanted to change the amount of time they spent on management. Most of them (16) wanted to reduce the amount of time. For 10 of these, this wish must have been unrealistic as they wanted to stop managing altogether. The two people who wanted to increase the amount of time, wanted only small increases of $5 \%$ and $10 \%$. The last of these was not currently doing any!

\section{Teaching and training}

Twelve people wished to change the proportion of time they spent teaching. Of these, six wanted to do less and six wanted to do more - usually small amounts ( $5 \%$ or $10 \%)$ both ways.

\section{Research}

Nobody wanted to spend less time doing research but 24 respondents wanted more time to spend on it. The increase they wanted was usually from $10 \%$ to $20 \%$, although in one case it was from $20 \%$ to $30 \%$.

\section{Private practice}

Eleven people wished to reorganise their private practice allocations. Six respondents wanted to stop doing it altogether: two wanted to increase it from $10 \%$ to $20 \%$; and two from zero to $10 \%$.

In summary, where people were discontented with the time they spent on the individual components of their jobs, it was primarily connected to the amount of time spent on general medicine and their wish to devote more time either to research or gastroenterology. Table III shows the relative size of the shifts people wished to make. To put these shifts into perspective, the Table includes all respondents.

\section{Career development}

The range of skills related to current jobs that respondents felt they did not have and would like to acquire was broad and diverse. Forty per cent said they did not have any requirements. Of the $60 \%$ who did feel they lacked some skills, seven wanted to acquire management skills. Twelve wanted ultrasound or endoscopic ultrasound skills, or both; five wanted computing and information technology skills; five wanted biliary manometry skills; four wanted therapeutic ERCP skills; and three wished to acquire skills related to nutrition. Other skills listed by individuals included: teaching, research, laser endoscopy, vasical banding (?), knowledge of molecular biology, colonoscopy, and liver histopathology.

Fewer respondents (34\%) felt the need to acquire new skills for their future careers. Of those who did, eight thought management and financial skills would be useful, and another three people wanted to acquire negotiating skills related to contracting. Six people thought teaching, research and audit skills would be useful. Three people wanted computing and information technology skills and one person thought the acquisition of leisure skills would be useful! 
TABLE IV Essential postgraduate skills ranked in priority order

\begin{tabular}{|c|c|c|c|c|c|c|c|c|c|c|c|c|}
\hline $\begin{array}{l}\text { Skills } \\
\text { Rank } \\
\text { order }\end{array}$ & $\begin{array}{l}D+T \\
\text { upper } \\
\text { gastrointestinal } \\
\text { endoscopy } \\
\%\end{array}$ & $\begin{array}{l}\text { Colonoscopy } \\
\%\end{array}$ & $\begin{array}{l}\underset{\%}{E R C P} \\
\end{array}$ & $\begin{array}{l}\text { Computer } \\
\text { and } \\
\text { information } \\
\text { technology } \\
\%\end{array}$ & $\begin{array}{l}\text { Diagnostic } \\
\text { ultrasound } \\
\%\end{array}$ & $\begin{array}{l}\text { Manometry } \\
\%\end{array}$ & $\begin{array}{l}\text { Nutrition } \\
\%\end{array}$ & $\begin{array}{l}\text { Liver } \\
\text { biopsy } \\
\%\end{array}$ & $\begin{array}{l}\text { Communication } \\
\%\end{array}$ & $\begin{array}{l}\text { Management } \\
\%\end{array}$ & $\begin{array}{l}\text { Teaching } \\
\%\end{array}$ & $\begin{array}{l}\text { Research } \\
\%\end{array}$ \\
\hline $\begin{array}{c}1 \\
2 \\
3 \\
4 \\
5 \\
6 \\
7 \\
8 \\
9 \\
10 \\
11 \\
12 \\
\text { NR }\end{array}$ & $\begin{array}{r}74 \\
8 \\
8 \\
4 \\
- \\
- \\
- \\
- \\
- \\
2 \\
- \\
2 \\
2\end{array}$ & $\begin{array}{r}15 \\
51 \\
11 \\
7 \\
4 \\
2 \\
- \\
- \\
2 \\
- \\
- \\
2 \\
6\end{array}$ & $\begin{array}{r}17 \\
8 \\
34 \\
6 \\
13 \\
8 \\
6 \\
- \\
- \\
4 \\
- \\
2 \\
2\end{array}$ & $\begin{array}{r}11 \\
2 \\
8 \\
9 \\
6 \\
11 \\
9 \\
13 \\
4 \\
8 \\
6 \\
6 \\
7\end{array}$ & $\begin{array}{r}6 \\
2 \\
- \\
8 \\
- \\
4 \\
6 \\
4 \\
6 \\
6 \\
23 \\
26 \\
9\end{array}$ & $\begin{array}{r}4 \\
2 \\
2 \\
2 \\
2 \\
- \\
- \\
4 \\
6 \\
17 \\
23 \\
32 \\
6\end{array}$ & $\begin{array}{r}9 \\
- \\
4 \\
2 \\
11 \\
8 \\
8 \\
8 \\
15 \\
21 \\
9 \\
2 \\
3\end{array}$ & $\begin{array}{r}15 \\
4 \\
8 \\
6 \\
8 \\
9 \\
2 \\
6 \\
11 \\
9 \\
8 \\
9 \\
5\end{array}$ & $\begin{array}{r}17 \\
4 \\
6 \\
11 \\
11 \\
9 \\
11 \\
11 \\
4 \\
4 \\
2 \\
4 \\
6\end{array}$ & $\begin{array}{r}8 \\
8 \\
8 \\
17 \\
13 \\
9 \\
9 \\
6 \\
6 \\
4 \\
4 \\
4 \\
-\end{array}$ & $\begin{array}{r}8 \\
4 \\
8 \\
2 \\
15 \\
17 \\
11 \\
17 \\
4 \\
8 \\
- \\
2 \\
4\end{array}$ & $\begin{array}{r}9 \\
4 \\
2 \\
13 \\
4 \\
8 \\
13 \\
15 \\
19 \\
4 \\
4 \\
\overline{5}\end{array}$ \\
\hline Number $=100 \%$ & 53 & 53 & 53 & 53 & 53 & 53 & 53 & 53 & 53 & 53 & 53 & 53 \\
\hline
\end{tabular}

Set out in this way, the Table shows little except that diagnostic and therapeutic $(D+T)$ upper gastrointestinal endoscopy skills are given top priority by three of four respondents. However, if the ranked items are divided into top six and bottom six proportions then added up, a clearer picture emerges. NR=not ranked.

TABLE V Postgraduate trainees essential skills - top six and bottom six ranked items

\begin{tabular}{|c|c|c|c|c|c|c|c|c|c|c|c|c|}
\hline$\frac{\text { Skills }}{\text { Totals }}$ & $\begin{array}{l}D+T \\
\text { upper } \\
\text { gastrointestinal } \\
\text { endoscopy } \\
\%\end{array}$ & $\begin{array}{l}\text { Colonoscopy } \\
\%\end{array}$ & $\underset{\%}{E R C P}$ & $\begin{array}{l}\text { Computer } \\
\text { and } \\
\text { information } \\
\text { technology } \\
\%\end{array}$ & $\begin{array}{l}\text { Diagnostic } \\
\text { ultrasound } \\
\%\end{array}$ & $\underset{\%}{\text { Manometry }}$ & $\begin{array}{l}\text { Nutrition } \\
\%\end{array}$ & $\begin{array}{l}\text { Liver } \\
\text { biopsy } \\
\%\end{array}$ & $\begin{array}{l}\text { Communication } \\
\%\end{array}$ & $\underset{\%}{\text { Management }}$ & $\begin{array}{l}\text { Teaching } \\
\%\end{array}$ & $\begin{array}{l}\text { Research } \\
\%\end{array}$ \\
\hline $\begin{array}{l}1-6 \\
6-12\end{array}$ & $\begin{array}{r}94 \\
4\end{array}$ & $\begin{array}{r}90 \\
4\end{array}$ & $\begin{array}{l}86 \\
12\end{array}$ & $\begin{array}{l}47 \\
46\end{array}$ & $\begin{array}{l}20 \\
76\end{array}$ & $\begin{array}{l}12 \\
82\end{array}$ & $\begin{array}{l}34 \\
63\end{array}$ & $\begin{array}{l}48 \\
45\end{array}$ & $\begin{array}{l}58 \\
36\end{array}$ & $\begin{array}{l}50 \\
33\end{array}$ & $\begin{array}{l}54 \\
40\end{array}$ & $\begin{array}{l}40 \\
55\end{array}$ \\
\hline
\end{tabular}

Working from the top and bottom, these proportions can be used to produce a rank order of skills considered essential to postgraduate training. How useful this is, will be for the group to decide.

\begin{tabular}{lll}
\hline 1 & & $\%$ \\
2 & Diagnostic and therapeutic gastrointestinal endoscopy & $(94)$ \\
3 & Colonoscopy & $(88)$ \\
4 & ERCP & $(86)$ \\
5 & Communications & $(58)$ \\
6 & Teaching & $(54)$ \\
7 & Management & $(50)$ \\
8 & Liver biopsy & $(48)$ \\
9 & Computing and information technology & $(46)$ \\
10 & Research & $(55)$ \\
11 & Nutrition & $(63)$ \\
12 & Diagnostic ultrasound & $(76)$ \\
\hline
\end{tabular}

\section{Essential skills for postgraduate trainees in the} future

Respondents were asked to indicate and rank in priority order, the skills that future trainee gastroenterologists should acquire. Table IV shows their response. Several (eight) people said that this was a pointless exercise but almost everyone completed the task (polite!). A few people ranked a number of items as equal first, or sixth, etc but this does not seriously affect the results.

\section{Appendix II}

\section{SAC guidelines - Gastroenterology}

Entry requirements

Applicants for Higher Medical Training (HMT) should have completed a minimum of two years general professional training (GPT) in approved posts and obtained the MRCP (UK) or (I). A period of experience in gastroenterology at SHO grade is considered desirable, before entry to HMT, although not essential. GPT should provide a minimum of 24 months involved with direct patient care at least 12 months of which should be concerned with acute unselected medical intake. Non-British/Irish graduates without the MRCP who compete for HMT posts must provide evidence of appropriate knowledge, training, and experience, particularly in the care of acute medical conditions.

Duration and organisation of training

The duration of HMT in gastroenterology is four years. One of those four years must be in general (internal) medicine $(\mathrm{G}(\mathrm{I}) \mathrm{M})$, as this training is essential for the practice of gastroenterology. Those who wish to obtain dual certification to include $G(I) M$ will require at least a fifth year in training. HMT will provide experience in both teaching hospital(s) or other major centres with academic activity and $\mathrm{DGH}(\mathrm{s})$. The programme to which the trainee is appointed will have named consultant trainers for each slot in the programme. In addition, one consultant within the same region will act as programme director to the trainee and will be appointed jointly by the postgraduate deans and the JCHMT.

A written record of training will be maintained by the trainee, to be countersigned by the relevant trainer annually; it will remain the property of the trainee but must be produced at the annual assessment and for the final SAC decision on certification.

Research

Research experience is encouraged and supported by the SAC and could count for up to a year of HMT if relevant to gastroenterology and undertaken in a department where the trainee has some clinical commitment. The SAC would be in a position to judge this. It will remain essential to acquire the full balance of clinical training.

Assessment

Assessment of trainees will be based upon the standard format of annual review. The recommendation of the postgraduate dean on the award of a CCST will be submitted to the JCHMT who retain the final responsibility for advising the GMC. 
General description of training

This will provide a balance of training in gastroenterology between district and university hospitals and in specialist units. There will be exposure to emergencies and a balance of outpatient and inpatien work, the detail of which is included in the curriculum below. There should be emphasis throughout on the importance of close cooperation with gastroenterology colleagues in other disciplines, especially surgery, radiology, and pathology and with general (internal) medicine. Trainees should acquire some experience in management skills, especially with reference to running a gastroenterology service.

Training in practical skills

Acquisition of skills as an endoscopist is essentia for training as a gastroenterologist but should be acknowledged as only part of that training. It is not a requirement for certification that a trainee becomes competent in every single diagnostic and therapeutic procedure, particularly at the expense of experience in the overall management of patients. Wherever endoscopy is taught, it should be as part of an overall gastroenterology service with cooperation between physician, surgeon, radiologist, and pathologist. While abdominal ultrasound is traditionally performed by radiologists in the UK, the SAC acknowledges that practical ultrasonography is a mandatory part of training for gastroenterology physicians in many parts of Europe. To bring any UK certificate into line with European Diploma requirements, we recommend some supervised training in ultrasonography.

\section{Curriculum}

\section{(a) General}

While not every aspect of training can be prescribed, it should include wide experience in the diagnosis and management of common gastrointestinal disorders such as acute and chronic gastrointestinal bleeding, peptic ulcers, oesophageal disease, infections, neoplasia, inflammatory bowel disease, jaundice, malabsorption, and pancreatic disease. The trainee should be familiar with the principles of enteral and parenteral nutrition. There should be extensive exposure to liver disease, both acute and chronic, with emphasis on the spectrum of alcohol related disorders. Trainees should become familiar with the indications for screening for gastrointestinal malignancy and interact with oncologists for the treatment and palliation of gastrointestinal cancers. There should be an understanding of gastrointestinal disease as found in the elderly. Wide outpatient experience must be obtained and familiarity gained with the management of functional bowel disorders. Throughout training there must be regular and close liaison with gastrointestinal surgeons in the joint management of patients and links with interested radiologists and histopathologists. There must be evidence of experience of the relevance of other pathological disciplines to gastroenterology, including microbiology, clinical chemistry, and haematology. Exposure to the management of patients with HIV infection should be sought. There must be evidence of continuing inpatients responsibility for patients with gastrointestinal disorders and a commitment to the management of emergencies.

Trainees should have the opportunity to gain particular added experience in specialised services such as liver transplantation, gastrointestinal motility, paediatric gastroenterology, AIDS, home parenteral nutrition, and the management of fulminant hepatic failure, but it is not considered essential that they should have wide experience in all of these.

\section{(b) Practical skills}

Oesophagogastroduodenoscopy (OGD) - the unit should be performing more than 1000 examinations per year. The trainee should attend at least weekly for six months and perform at least 150-200 diagnostic examinations under a degree of supervision, and then undertake further examinations, when judged competent, with a degree of independence in selected cases, to a total minimum of 300 examinations. Therapeutic endoscopy of the upper gastrointestinal tract requires further specific training under supervision, requiring 30 variceal injections and other haemostatic techniques. The trainee should have knowledge of the indications for the technique of endoscopic placement of feeding gastrostomy tubes.

Colonoscopy - as with OGD, training in service is most important. Training units must undertake at least 200 procedures per year to allow adequate opportunities for training. Trainees should assist at a minimum of 50 colonoscopies and complete a further 50 under supervision. The ability to perform polypectomy correctly and understand the principles of diathermy is essential. Experience in fibreoptic sigmoidoscopy does not imply expertise with a colonoscope. Rigid sigmoidoscopy remains an essential skill and exposure to a minimum of 100 procedures is recommended.

$E R C P$ - before starting ERCP a sound experience of OGD is essential. To provide adequate experience training centres should undertake at least 200 procedures per year. There should be liaison with radiologists skilled in imaging and interventional techniques. Joint meetings of different disciplines should be held to discuss cases. The experience to achieve competence will vary, but a high percentage of successful pancreatic and biliary diagnostic cannulation is essential before procedures are performed independently. A minimum experience is likely to be 150 cases. Ability to interpret the radiological findings is essential. If the trainee is to proceed to an independent ERCP practice, after mastering diagnostic ERCP, it is essential to proceed to a competence in papillotomy for stone extraction and in stent insertion.

Liver biopsy - all trainees should be thoroughly familiar with the indications, methods, and risks of percutaneous liver biopsy including that performed under ultrasound control, and should have practical experience of a minimum of 50 procedures.

Intubation techniques - exposure to the principles and practice of intubation for oesophageal motility, 24 hour $\mathrm{pH}$ monitoring, and acid output tests should be sought.

Abdominal ultrasonography - supervised experience of a minimum of 300 examinations is recommended to align with European Diploma requirements.

Courses - trainees should attend courses in basic and therapeutic endoscopy, approved by the British Society of Gastroenterology. Topics covered will include patient care, cleaning, maintenance and disinfection of instruments, electrical hazards, recognition and management of complications, and therapeutic procedures such as stricture dilatation and variceal injection. The general administration and management of an endoscopy service will be covered. Further courses on colonoscopy and ERCP should be attended as appropriate for the trainee. 